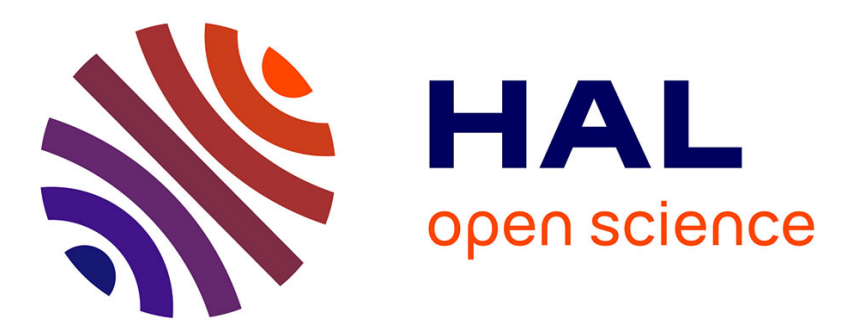

\title{
TIME DOMAIN SIMULATIONS OF STRING INSTRUMENTS. A LINK BETWEEN PHYSICAL MODELING AND MUSICAL PERCEPTION
}

A. Chaigne, A. Askenfelt, E. Jansson

\section{- To cite this version:}

A. Chaigne, A. Askenfelt, E. Jansson. TIME DOMAIN SIMULATIONS OF STRING INSTRUMENTS. A LINK BETWEEN PHYSICAL MODELING AND MUSICAL PERCEPTION. Journal de Physique IV Proceedings, 1992, 02 (C1), pp.C1-51-C1-54. 10.1051/.jp4:1992107 • jpa-00251049

HAL Id: jpa-00251049

https://hal.science/jpa-00251049

Submitted on 1 Jan 1992

HAL is a multi-disciplinary open access archive for the deposit and dissemination of scientific research documents, whether they are published or not. The documents may come from teaching and research institutions in France or abroad, or from public or private research centers.
L'archive ouverte pluridisciplinaire HAL, est destinée au dépôt et à la diffusion de documents scientifiques de niveau recherche, publiés ou non, émanant des établissements d'enseignement et de recherche français ou étrangers, des laboratoires publics ou privés. 


\title{
TIME DOMAIN SIMULATIONS OF STRING INSTRUMENTS. A LINK BETWEEN PHYSICAL MODELING AND MUSICAL PERCEPTION
}

\author{
A. CHAIGNE, A. ASKENFELT* and E. JANSSON* \\ Groupe Acoustique, Département Signal, TELECOM Paris, F-75634 Paris cedex 13, France \\ *Dept. of Speech Communication and Music Acoustics, Royal Institute of Technology, Box 70014, \\ S-100 44 Stockholm, Sweden
}

\begin{abstract}
String vibrations are simulated in the time-domain, using appropriate finite differences schemes. Initial and boundary conditions are derived from the physics of string instruments. A number of physical constants are modified step by step, and listening tests are performed, in order to evaluate their perceptual relevance.
\end{abstract}

\section{Time domain simulations.}

With the help of appropriate finite differences schemes, the transverse wave equation of a damped stiff string can be put into a discrete form in space and time. Modeling further the excitation (plucking, striking or bowing,...) and the boundary conditions leads to realistic simulations of string instruments [1], [2]. It is of the utmost importance here to notice that the model itself is not sufficient, and will not bear any convincing sounds unless correct values of the physical constants are introduced into the equations of motion. Therefore, preliminary measurements on real instruments are needed. A second difficulty arises from the fact that a number of physical laws,"'such as those governing the damping, which are fairly well described by continuous equations, cannot be put in a straightforward way into discrete forms. As a consequence, it is often necessary to describe the experimentally measured parameters with the help of asymptotic approximations which are more compatible with the selected numerical scheme. Fig. 1 shows, for example, the law of damping with frequency for a nylon guitar A-string and the asymptotic approximation used for the synthesis.

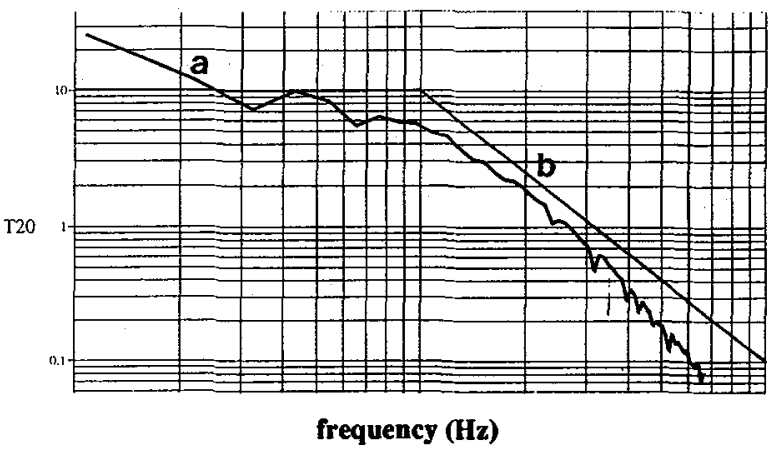

Figure 1. Decay times T20 (at $-20 \mathrm{~dB}$, in s) for an Aranjuez guitar A-string vs frequency.

a) Measurements ; b) Asymptotic model : $b_{1}+b_{3} \omega^{2}$. 


\section{Exploring the physies of string instruments.}

As it is well-known, the string itself doesn't produce any sound, and needs to be coupled with a resonator (guitar or violin body, piano soundboard,...). Because of this coupling, the time history of mechanical quantities, such as velocity or acceleration at the bridge, are drastically changed in comparison with force or velocity on the string. The coupling between string partials and body modes has been widely investigated by several authors in the frequency-domain. Through our time-domain simulations, it becomes now possible to observe further the effects of this coupling on transients. An illustration of these effects is given in Figure 2, which represents the modifications in the waveform of guitar onsets when the fundamental frequency $f_{1}$ of the string varies within the range $[200,250 \mathrm{~Hz}]$, for a given resonance box. The resulting dynamical changes are clearly perceived. Another kind of temporal fluctuations can be observed by testing the influence of the Q-values of the body resonances on the time history of the synthesized sounds. Thus, starting from a reference sound with typical Qvalue (say $Q=40$ for the type of wood used in lutherie), one can explore the sensitivity of the human ear to this physical quantity.
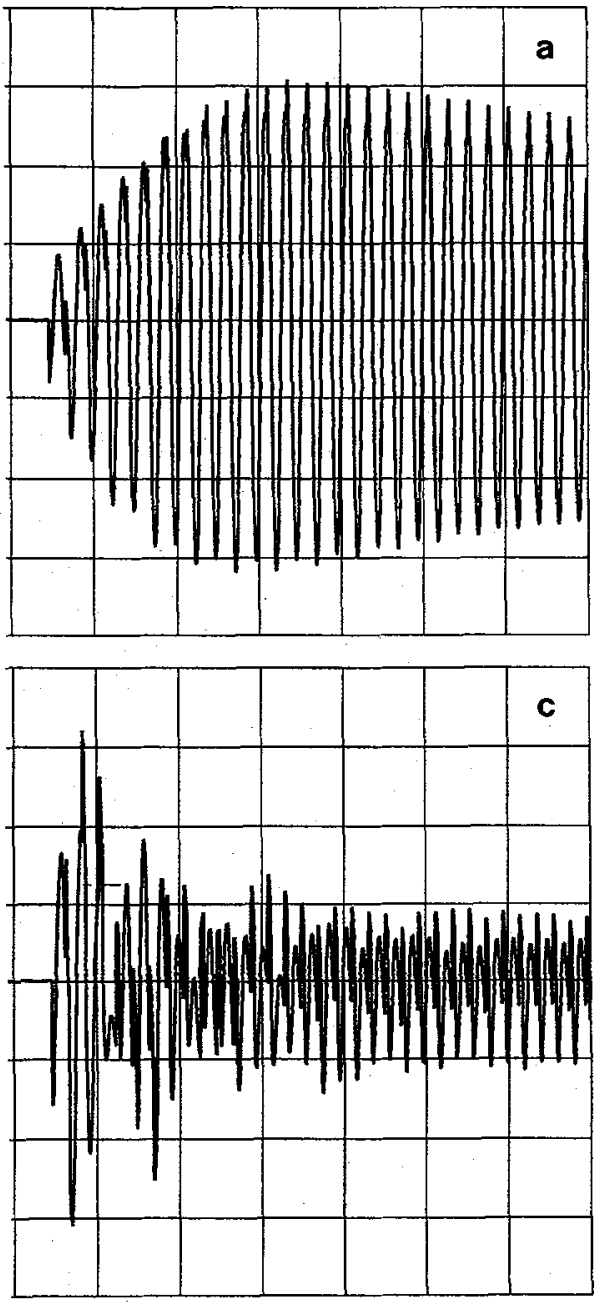
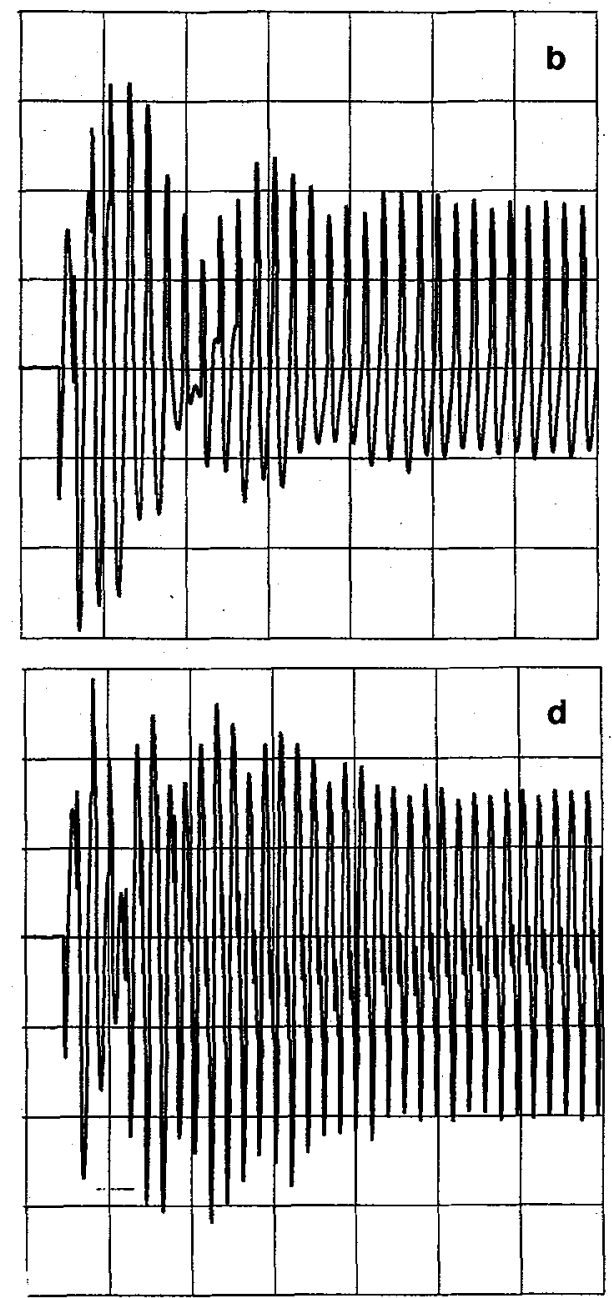

Figure 2 : simulated guitar onsets. a) $f_{1}=200 \mathrm{~Hz}$, b) $f_{1}=220 \mathrm{~Hz}$, c) $f_{1}=240 \mathrm{~Hz}$, d) $f_{1}=250 \mathrm{~Hz}$. 
Another application of time-domain simulations is the creation of fanciful instruments, in continuity with the real world, through variation of a given physical parameter. In order to make a link with the art of craftsmen, we investigated systematically the effects of varying the volume of air enclosed in a given guitar box on the sound produced. The underlying continuous model is derived from a work by Christensen and Vistisen [3]. The corresponding discrete algorithm has been presented in a previous paper by the first author [2]. The different values of the volume $\mathrm{V}$ are given below. The lowest air frequency $f_{a}$ varies as $V^{-1 / 2}$. The lowest frequency $f_{p}$ is given by [3] :

$$
f_{p}^{2}=f_{p, 0}{ }^{2}+f_{a}^{2}
$$

where $\quad f_{p, 0}$ is the lowest frequency of the plate, in the absence of air loading.

The numerical values used for the demonstration series are the following :

\begin{tabular}{|l|l|l|l|l|l|l|l|l|l|l|}
\hline $\mathrm{V}$ & 26 & 21.8 & 18.4 & 15.5 & 13 & 10.9 & 9.2 & 7.7 & 6.5 & liters \\
\hline $\mathrm{f}_{\mathrm{a}}$ & 72 & 78.5 & 85.6 & 93.4 & 102 & 111 & 121.1 & 132.0 & 144 & $\mathrm{~Hz}$ \\
\hline $\mathrm{f}_{\mathrm{p}}$ & 182 & 184.5 & 187.7 & 191.3 & 196 & 200.5 & 106.3 & 212.9 & 221 & $\mathrm{~Hz}$ \\
\hline
\end{tabular}

The parameters of the reference sound (bold type) were measured on a real guitar. The sounds of the series corresponding to the two lowest values of $\mathrm{V}$ exhibit strong inharmonicity, which is not compatible with high-quality instruments.

The third example presented here is related to the physics of piano strings. In a previous paper, Askenfelt and Jansson presented string velocity waveforms for a C4-string played with C7, C4 and C2 hammers. The modifications of the waveforms resulting from changing the hardness of the hammers can be clearly seen in Figure 4-a. Earlier physical experiments have provided the nonlinear compression law of the hammer felt, written in the form $F=K \delta$ P. Figure 4-b shows the results of the simulation with the following numerical values :

\begin{tabular}{|l|l|l|l|}
\hline Hammer & $\mathrm{C} 7$ & $\mathrm{C} 4$ & $\mathrm{C} 2$ \\
\hline $\mathrm{K}$ & $1.010^{12}$ & $4.510^{9}$ & $2.010^{8}$ \\
\hline $\mathrm{p}$ & 3.0 & 2.5 & 2.3 \\
\hline
\end{tabular}
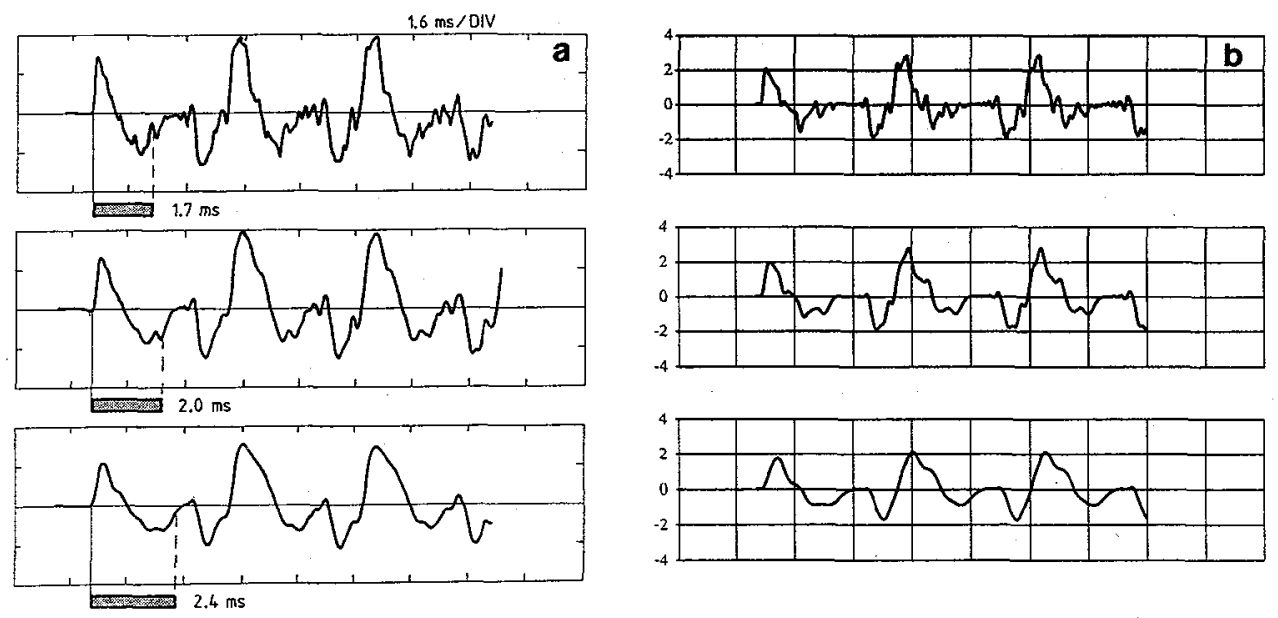

Figure 3. Piano string velocities (arbitrary units) for tone $\mathrm{C} 4$ played with $\mathrm{C} 7, \mathrm{C} 4$, and $\mathrm{C} 2$ hammers a) measured; b) simulated. Time scale : $16 \mathrm{~ms}$. 


\section{Perceptual evaluation of the synthesis.}

It turns out that measuring and comparing real and synthesized waveforms in both the time and frequency domain is not sufficient to assess the perceptual relevance of a given simulation. Furthermore, an auditory evaluation is an efficient step for limiting as much as possible the complexity of the underlying physical model. In order to evaluate the quality of simulated guitar tones, a subjective test was built in two steps. A short musical fragment was played by the computer through headphones. The first purpose of the test was to identify the type of instrument in the following list : piano, harp, harpsichord, classical guitar, electric guitar, lute, cymbalum, zyther, violin played pizz., cello played pizz., viola played pizz., banjo. A total of 20 persons (12 musicians and 8 non-musicians) trained in listening tests participated to this evaluation. The classical guitar was selected as the best candidate by 18 participants, one listener selected the lute, and one the harp. In a second step, the listeners had to evaluate the degree of realism of the simulation on the subjective scale given below :

\begin{tabular}{|c|c|c|c|c|c|}
\hline 1 & 2 & 3 & 4 & 5 & 6 \\
\hline very bad & bad & $<$ fair & $>$ fair & good & excellent \\
\hline
\end{tabular}

The histogram of the subjective answers is given in Figure 4. From these results, it can be concluded that the model yields enough information for the recognition of the simulated instrument without ambiguity, and further that the tone quality of the synthesis can be compared to that of real instruments.

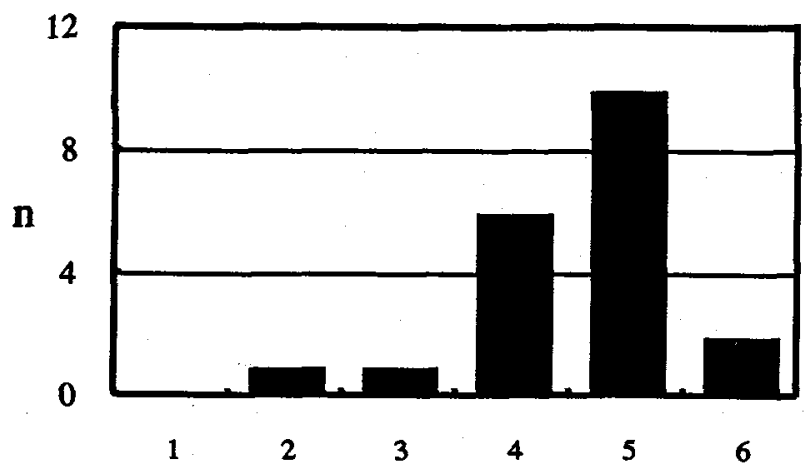

Figure 4. Histogram of subjective answers.

Acknowledgements.

Part of the presently reported work has been conducted while the first author was a guest researcher at the Department of Speech Communication and Music Acoustics, KTH, Stockholm. Special thanks are due to the members of the Speech and Hearing groups of this department who participate to the listening tests.

\section{References.}

[1] A. Chaigne, A. Askenfelt \& E. Jansson, "temporal synthesis of string instrument tones", STLQPSR 4/1990, 81-100.

[2] A. Chaigne, "On the use of finite differences for the synthesis of musical transients. Application to plucked stringed instruments", J. Acoustique, 1991 (submitted).

[3] O. Christensen \& B.B. Vistisen, "Simple model for low-frequency guitar function", J. Acoust. Soc. Am. 68, 758-766, 1980.

[4] A. Askenfelt \& E. Jansson, "From touch to string vibrations -- The initial course of the piano tone", STL-QPSR 1/1988, 31-109. 